\title{
Oikos: Plantando amor e sabedoria: colhendo esperança e educação
}

\author{
Raquel de Melo Ferreira ${ }^{1}$
}

\section{Introdução}

O projeto Oikos nasce da iniciativa de alunas do curso de MBAe graduação da Faculdade AntonioMeneghetti - localizada no Distrito Recanto Maestro, em meados do ano de 2011.

O projeto iniciou o seu desenvolvimento procurando estimular a formação de homens responsáveis por ações ambientais, éticas e de respeito à natureza, resgatando e promovendo os valores humanistas para uma dialética de estética e inteligência com o nosso planeta, promovendo uma ecobiologia .

O Projeto Oikos é realizado e mantido pela Fundação AntonioMeneghetti que tem desde a sua criação, a educação, o incentivo à cultura e a pesquisa ontopsicológica como prioridades. Ademais tem como critério apoiar projetos que valorizam o ser humano, a sociedade, a ciência, a economia, a arte e a cultura seguindo os preceitos definidos pelas Organizações das Nações Unidas (ONU) e a divulgação da Ciência Ontopsicológica.

O Recanto do Maestro foi reconhecido, no dia 2 de julho de 2007 - na sede da ONU, em Genebra, na Suíça, como um Centro Integral de Desenvolvimento Humano e Social. Os Objetivos de Desenvolvimento do Milênio (ODM) foram medidas definidas pela Cúpula do Milênio; realizada no ano de 2000, em Nova Iorque, com líderes de 191 países. Na ocasião, foi colocado como prioridade eliminar a extrema pobreza e a fome no planeta, até 2015. Para tanto, estabeleceram-se oitos objetivos, englobando propostas que iam desde atingir a educação primária universal até garantir a sustentabilidade ambiental. Em 2015, uma nova agenda de ações foi lançada. Os 17 Objetivos de Desenvolvimento Sustentáveis (ODS) trazem uma grande escala de ambição construída pelo legado dos ODM e concluirão o que aqueles não conseguiram alcançar.

\footnotetext{
${ }^{1}$ Acadêmico da segunda turma do Curso de Bacharelado em Ontopsicologia. Artigo produzido como Pequena Tese do Módulo 1 (período de março a outubro de 2016). Faculdade Antonio Meneghetti (AMF).
} 
Dessa forma, o Projeto Oikos contempla alguns ODS, como uma Educação de Qualidade (ODS 4), Cidades e Comunidades Sustentáveis (ODS 11), Boa saúde e Bem estar (ODS 3), Vida sobre a terra(ODS 15), Consumo e produção responsáveis (ODS 12), Fome zero (ODS 2), Erradicação da pobreza (ODS 1), Combate às alterações climáticas (ODS 13) e Parceria em prol das metas (ODS 17).

Em 2011, o projeto Oikos recebeu o prêmio Fecomércio de Sustentabilidades na categoria academia/aluno, em que a premiação tinha como foco contemplar as ações que enfocavam os desafios da sustentabilidade e suas aplicações para o ambiente empresarial. Com mais de 300 inscritos de todo o país, definido por importantes órgãos, dos 28 finalistas, o Projeto Oikos foi escolhido entre três finalistas e recebeu à época, um prêmio no valor de $\mathrm{R} \$ 15$ mil reais em título de previdência que foi destinado à ampliação e melhoria do projeto.

O projeto Oikos ficou por um período somente realizando pequenas atividades, porém, intensificou as suas atividades em 2016 quando começou a realizar ações em dois municípios da Quarta Colônia onde o Distrito Recanto Maestro está localizado. Nos municípios de Agudo e Dona Francisca, as atividades ocorreram de forma prática e teórica, sendo que foram atendidas três escolas, duas no município de Agudo (uma delas somente no terceiro semestre) e uma no município de Dona Francisca, atendendo, assim, 114 alunos respondendo de forma positiva a oportunidade de replicar o projeto para outros municípios.

No ano de 2017, o projeto vem atendendo aproximadamente 400 crianças/jovens em seis municípios, com oito escolas participantes. As atividades continuam ocorrendo de forma prática e teórica em todas as escolas, cada uma sendo atendida de acordo com a realidade da comunidade escolar.

\footnotetext{
O projeto busca direcionar que cada aluno desenvolva uma melhor significativa da sua qualidade de vida, visto que modifica suas atitudes e práticas pessoais a partir do momento que começa a entender a importância da sua participação cidadã na construção de sociedades mais sustentáveis. Motivando, por meio dos alunos, a criação de hortas em suas próprias casas reduzindo o desperdício e consequentemente aumenta o bem-estar. (Anuário Fundação Antonio Meneghetti, 2016).
}

O projeto Oikos possui um trabalho ainda mais amplo, em que realiza desde o início de suas atividades uma conscientização sobre o recolhimento de pilhas alcalinas e baterias de celulares, sendo que a Faculdade Antonio Meneghetti possui coletores específicos para o recolhimento do material que, depois, é levado para uma empresa para o 
descarte correto. Faz-se também um trabalho de conscientização sobre a coleta de resíduos secos e orgânicos com os moradores do Distrito Recanto Maestro. Os moradores receberam uma cartilha explicativa, ensinando sobre a coleta seletiva, recebendo, assim, lixeiras para o armazenamento correto, contribuindo para um local ainda mais consciente da importância de preservação do meio ambiente.

\section{Fundamentação teórica}

O Projeto Oikos, apesar de toda a conscientização do meio ambiente, tenta ensinar os seus alunos e mostrar aos professores e toda a comunidade escolar a pedagogia ontopsicológica, que dá recursos aos alunos para.

\footnotetext{
Descobrir a si mesmo em base à identidade ôntica, ou seja, saber-se como é e não como pensa. É preciso chegar com a boa vontade, a humildade e a Ontopsicologia pode auxiliar porque é um método radical, técnico, lógico, que faz ver rapidamente se você é ou não é, se é você ou é um outro. Portanto você jovem, cedo ou tarde, vai em busca de si mesmo. (MENEGHETTI, 2014, p. 86).
}

Não adianta pensar no meio ambiente, se não pensar em si próprio, isto é, a criança/ jovem somente cuidará e preservará o meio ambiente se sentir-se parte dele, se começar avaliar as suas atitudes, naquilo que vem mudando com a sua aprendizagem, pois assim crianças e jovens pensam e geram uma atitude de mudança transformadora.

Sendo assim, o projeto busca com as atividades educar todos que estão inseridos nele de uma forma diferente, isto é, de uma forma de conhecimento do seu eu, gerando uma forma protagonista:

O escopo prático é educar o sujeito a fazer e a saber si mesmo: fazer uma pedagogia de si mesmo como pessoa líder no mundo, educar em Eu lógico histórico com capacidades e condutas vencedoras(MENEGHETTI, 2014, p. 14).

Espera-se pois condutas vencedoras de um ser humano vencedor e transformador, que não recicla somente resíduo, mas que recicla atitudes e realmente preserva o meio ambiente que está inserido de forma responsável.

O Em Si ôntico é o critério elementar da natureza que intenciona o projeto humano baseado na constante $\mathrm{H}$ ou intencionalidade primeira da natureza relacionada ao homem, sobre o qual, historicamente (meme histórico) e virulogicamente, apóiam-se informações que imitam relações de realidade, mas 
são espelhos sem o original ou conformidade funcional ao projeto de natureza. Feixe de esteriótipos, complexos, desvios não são baseados sobre a natureza em si do homem, mas sobre aquelas sobreposições informáticas (doxa societária) que pouco a pouco, por meio da família, foram introduzidas e estabilizadas como Eu lógico histórico, portanto como o caracterial consciente voluntário que efetua de fato o determinismo histórico do indivíduo (MENEGHETTI,2014 p. 14-15).

A criança aprende desde pequena a uniformar-se a essa mêmica societária imposta na família, adapta-se aos esquemas externos, sofre o parasitismo violento do meme social por meio do qual é alfabetizada e adapta-se a esse esquema fechado. Aprende o meme e perde a informação ôntica. $\mathrm{O}$ Eu lógico histórico é estruturado pelo conjunto da mamética social; por isso, quando adultos, para recuperar a nós mesmos, devemos distinguir as informações ônticas das informações meméticas (MENEGHETTI, 2014 p. 15).

O que se quer mostrar é que a criança muitas vezes segue os estereótipos do ambiente em que ela vive, onde é normal jogar lixo em qualquer lugar, em que não se vê problema algum em fazer torres de lixo em qualquer lugar onde o ideal são os aterros sanitários. As crianças, por outro lado, aprendem que certos alimentos são ruins sem ao menos tê-los experimentados, pois membros de sua família dizem que o gosto é ruim, mas muitas vezes, nem eles mesmos experimentaram.

\begin{abstract}
A pedagogia ontopsicológica tem como tarefa redescobrir, isolar a sinalética do projeto - base da natureza ou Em Si ôntico (MENEGHETTI, 2014 p. 15), buscando dessa forma que a criança tenha a elaboração da construção e responsabilidade Social.

A declaração de Tbilisi reconheceu o ensino formal como um dos eixos centrais da educação ambiental. Ou seja, fica reconhecida a importância do papel do professor. A escola passa a ser considerada um centro de formação em educação ambiental. (WWF,1997 p.85).
\end{abstract}

Sabemos que esta transformação não acontece da noite para o dia, que existe um longo caminho a trilhar, porém, sabemos que é possível, pois o ser humano é um agente transformador e as crianças são agentes multiplicadores e serão eles que estarão fazendo a diferença nas próximas décadas fazendo com que este planeta não sofra mais do que já está sofrendo e como faremos isso esclarecendo e com projetos de atuação político-pedagógico que busquem encaminhar nessa direção.

Temos como uma dessa ferramenta os Parâmetros Curriculares Nacionais em Temas Transversais no item Meio Ambiente que nos dá subsídios para trabalhar juntamente nas escolas este tema e que também tem como objetivo alertar para a conscientização: 
São grandes os desafios a enfrentar quando se procura direcionar as ações para a melhoria das condições de vida no mundo. Um deles é relativo à mudança de atitudes na interação com o patrimônio básico para a vida humana: o meio ambiente.

Os alunos podem ser nota 10 nas provas, mas, ainda assim, jogar lixo na rua, pescar peixes-fêmeas prontas para reproduzir, atear fogo no mato indiscriminadamente, ou realizar outro tipo de ação danosa, seja por perceberem a extensão dessas ações ou por não se sentirem responsáveis pelo mundo que vivem.

A solução dos problemas ambientais tem sido considerada cada vez mais urgente para garantir o futuro da humanidade e depende da relação que se estabelece entre sociedade/natureza, tanto na dimensão coletiva quanto na individual. (PCN, 1998 p. 169)

Essa é a diferença é sentir que são partes desse mundo e sendo assim são responsáveis por ele, pois se faz pertencente e assim se faz transformador. É aprender como as abelhas vivem e tentar reproduzir para si a forma de respeito e organização em que elas vivem por exemplo.

Muitos de nossos alunos vivem ou tem familiares próximos que vivem no meio rural e que plantam cana-de-açúcar e produzem o melaço e o açúcar mascavo, mas que as crianças/jovens não sabem que este processo é o início para a produção do etanol que é uma energia renovável e que é importante para o meio ambiente. E esta criança com certeza após este conhecimento irá explicar para seus familiares, colegas e a comunidade em que está inserida a importância dessa gramínea e com certeza despertará para as pessoas um novo olhar pois terão o entendimento como diz o texto nos PCN a dimensão coletiva quanto a individual.

Esta dimensão de conhecimento também deve ser com relação que o meio ambiente está passando por este declínio porque o ser humano é o responsável e que se não mudar seus hábitos e atitudes seremos nós mesmo os maiores prejudicados.

\begin{abstract}
A problematização e o entendimento das conseqüências de alterações no ambiente permitem compreendê-las como algo produzido pela mão humana, em determinados contextos históricos, e comportam diferentes caminhos de superação. Dessa forma, o debate na escola pode incluir a dimensão política e a perspectiva da busca de soluções para situações como a sobrevivência de pescadores na época da desova dos peixes, a falta de saneamento básico adequado ou as enchentes que tantos danos trazem à população. (PCN,1998 p. 169).
\end{abstract}

Porém, falar de meio ambiente na sala de aula é um assunto inesgotável, pois um assunto está vinculado ao outro e um dos assuntos em que sempre é abordado com os 
alunos é sobre o consumo ilimitado que o ser humano possui principalmente os alunos do Fundamental II que estão ente as idades de 11 a 14 anos de idade e que são os que estão mais vulneráveis a esta consumação, pois muitos deles querem estar sempre consumindo o que a moda acaba ditando, como estar com o tênis e a roupa da moda e ter o celular de última geração sem perceber que estão simplesmente sendo meros consumidores de um capitalismo que muitas vezes não acaba preocupando se com o meio ambiente.

Quando abordamos estes assuntos na sala de aula muitos alunos não percebem este ciclo vicioso, consumista e não percebem que muitas vezes o que não utilizamos mais irá prejudicar o meio ambiente, pois não podemos trocar um celular e jogar o velho no lixo convencional, saber que uma peça de roupa pode ser doada, e não refletem que toda esta decomposição levará um tempo muitas vezes extenso para concluir. Então propomos aos alunos a concluir: Eu preciso mesmo daquele tênis? Daquele objeto? Como foi o processo de construção daquele objeto? Foram utilizados produtos químicos que preservaram o meio ambiente? Em quanto tempo ocorrerá a decomposição?

Os alunos precisam entender que o bem-estar das pessoas não é diretamente proporcional à maior quantidade de bens consumidos (PCN, 1998, p.177) que é preciso gerar renda, precisamos de tecnologia e de crescimento, mas desde que este processo seja consciente.

\footnotetext{
É fundamental a sociedade impor regras de crescimento, à exploração e à distribuição dos recursos de modo a garantir a qualidade de vida daqueles que deles dependam e dos que vivem no espaço de entorno em que são extraídos ou processados. Portanto, deve-se cuidar, para que o uso econômico dos bens da Terra pelos seres humanos tenha caráter de conservação, isto é, que gere o menor impacto possível e respeite as condições de máxima renovabilidade dos recursos. Nos documentos assinados pela grande maioria dos países do mundo, incluindose o Brasil, fala-se em garantir o acesso de todos aos bens econômicos e culturais necessários ao desenvolvimento pessoal e a uma boa qualidade de vida, relacionando - com o conceito de sustentabilidade. (PCN, 1998, p. 177)
}

Porém, muitas empresas já vêm mudando o modo de produzir seus produtos, tendo como base a sustentabilidade que é um termo que vem adquirindo uma grande importância e que vem mudando a rotina de muitas empresas. Esse conceito acaba gerando também muitos recursos financeiros, pois a população através das campanhas e dos trabalhos realizados nas escolas vem fazendo com que as pessoas busquem produtos orgânicos ou que produzem um menor impacto possível ao meio ambiente desta forma as empresas precisam mudar, pois os consumidores estão cada vez mais exigentes. 
Muitas das empresas já possuem indicadores do consumo específico de energia e oferecem programas de treinamento ambiental a seus funcionários (REVISTA VISÃO AMBIENTAL, 2010 p. 7) como ocorrem também outras pesquisas como redução de emissão de gases de efeito estufa e fontes renováveis de energia, sendo eles todos os itens estudados pelos alunos do Projeto OIKOS desde o $3 .^{\circ}$ ano do Ensino Fundamental I.

\section{Metodologia}

A coordenação do Projeto Oikos visitou as seis Secretarias de Educação dos municípios pertencentes ou próximos da Quarta Colônia passíveis para receber o projeto, respeitando sempre a logística da região e conversando com os secretários sobre quais as escolas acreditavam precisar do projeto. Ao mesmo tempo, a coordenação estudava as escolas que acreditava terem mais necessidades, tendo como foco a vulnerabilidade social, o "gosto pela terra". Também se buscou analisar nessas visitas a relação das escolas com o meio ambiente, se as escolas já haviam realizado trabalhos sobre conscientização pelo meio ambiente ou se tinham nenhum/pouquíssimo conhecimento sobre a temática. Sempre ao término das reuniões chegava-se a um consenso comum sobre a escola ou escolas escolhidas.

O segundo passo foi conversar com a direção das escolas, apresentando-se para equipes diretivas, professores, pais e alunos, o que é o projeto, porque ele existe, quais os objetivos e os benefícios que ele traz para toda a comunidade escolar. Como muitos pais trabalham fora e não podiam ir até as escolas, também foi enviada uma carta explicativa deixando os contatos da coordenação do Projeto Oikos. Com a equipe diretiva na maioria das escolas foi conversado em reunião pedagógica, pedindo assim sugestões e apoio dos professores, sempre buscando engajar os assuntos trabalhos pelo projeto com toda a grade curricular da escola. Há sempre uma conversa com todos os alunos de forma pessoal, explicando que caso alguém tivesse alguma dúvida poderia entrar em contato com os profissionais do projeto para quaisquer esclarecimentos.

Um exemplo desse engajamento foi o tema anual de trabalho de uma escola que foi voltado para o meio ambiente. Cada sala ficou responsável por cuidar de um espaço da escola, buscando reciclar, preservar e melhorar. Houve o caso de uma turma que ficou responsável por uma sanga que fica no terreno da escola e que em dias de chuva prejudica o pátio da escola. Em parceria com a prefeitura do município será feito um reflorestamento 
com contenção das águas, buscando, assim, ainda preservar a história daquele local. Como é uma escola antiga e muitos alunos no passado brincavam naquele local, o ambiente ali gera uma recordação afetiva e histórica do local que busca ser preservada.

As atividades nas escolas começaram de forma gradativa, para que pudessem ocorrer de forma segura e planejada. As primeiras atividades começaram no início no mês de março e as últimas escolas deram início as suas atividades no mês de maio, somando assim quase 400 crianças/jovens.

As atividades nas escolas são realizadas por dois profissionais, sendo uma pedagoga e um engenheiro florestal. A pedagoga atende os alunos do ensino fundamental I ( $3 .^{\circ}$ ao $5 .^{\circ}$ ) e o engenheiro florestal é responsável pelos alunos do fundamental II $\left(6 .^{\circ}\right.$ ao $\left.9 .^{\circ}\right)$ tendo aulas mais práticas. Em algumas situações, também ele realiza atividades com os alunos do fundamental I.

O projeto, dessa forma acaba sendo dividido em duas partes uma turma que possui mais aulas teóricas (porém, também participando de aulas práticas) e outra turma que possui mais aulas práticas (porém, também recebendo aulas teóricas).

As aulas ocorrem nos municípios de Agudo, Dona Francisca, Faxinal do Soturno, Paraíso do Sul, Restinga Sêca e São João do Polêsine, sendo nas seguintes escolas:
a) Agudo: EMEF Santos Reis e EMEF Alberto Pasqualini
b) Dona Francisca: EMEF Antonio Luiz Barchet
c) Faxinal do Soturno: EMEF Santa Rita de Cássia
d) Paraíso do Sul: EEEM Presidente Afonso Pena
e) Restinga Sêca: EMEF Manuel Albino de Carvalho e EMEF Dezidério Fuzer
f) São João do Polêsine: EMEF La Salle

No início das aulas, os alunos recebem uma pasta com a identificação do Projeto para guardarem as atividades realizadas e uma camiseta para utilizar nas atividades. Todos os alunos recebem um lápis semente, que posteriormente poderá ser plantada semestes, após germinação, produz hortaliças, estimulando o aluno a acompanhar o ciclo de vida do vegetal.

As aulas ocorrem quinzenalmente em um período que compreende de 60 a 90 minutos, dependendo da grade curricular da escola e da oportunidade que a equipe diretiva disponibiliza, pois a Fundação respeita muito a equipe diretiva das escolas e a rotina de 
cada uma delas, deixando bem claro que se está na escola para agregar conteúdo para os alunos e não prejudicar a rotina escolar.

Nas escolas que possuem espaço adequado para a construção de uma horta horizontal as hortaliças são plantadas diretamente na terra. Porém, naquelas escolas emque não há essa possibilidade, são construídas hortas verticais, com estrutura de ferro que sustentam canteiros feitos com canos de PVC de diâmetro propício para o cultivo das hortaliças.

Sendo assim, são plantados hortaliças e ervas medicinais. O projeto também busca revitalizar as escolas com canteiros de flores, propiciando aos alunos um lugar mais alegre e colorido. Quando possível também são plantados árvores frutíferas pelos pátios das escolas. Todas essas atividades são realizadas pelos alunos sem nenhum custo para eles ou para a escola, já que o material necessário é disponibilizado pela Fundação Antonio Meneghetti.

Nas aulas teóricas, são trabalhados assuntos que muitas vezes, são poucos estudados nas aulas de ciências ou meio ambiente e que, todavia, são de suma importância para o desenvolvimento do ser humano responsável com si próprio e com o meio ambiente. São, entre outras temáticas do Projeto, energia renováveis e não renováveis, a importância da água, cana-de-açúcar/etanol, importância da Flora brasileira, abelhas, florestas, alimentação saudável e outros assuntos referentes ao meio ambiente.

Os alunos são estimulados a multiplicar o que eles estão aprendendo e buscar inserir em sua vida prática e cotidiana, com base em suas realidades e suas vivências. Muitos alunos possuem, ainda, em suas casas ou de familiares próximos, hortas e pomares, porém, não são estimulados a praticar e vivenciar essa experiência que é de suma importância para o desenvolvimento humano, sustentável e protagonista, ou seja, desenvolvimento ecobiologico.

Outra carência que também é muito observada durante as aulas práticas e teóricas é alimentação saudável. Muitos alunos têm como base de alimentação carboidrato, gordura, sódio e açúcares, itens que devem ser utilizados com moderação. Muitos alunos, portanto, acabam não ingerindo alimentos orgânicos (frutas e verduras) porque não são estimulados pelos seus próprios familiares e relatam que não comem porque não gostam, sem ter, muitas vezes, experimentado.

Toda a produção das hortas é consumida na merenda das próprias escolas e também, dependendo da demanda, pode ser levada para casa, para que possa ser preparada 
e degustada pelos alunos e seus familiares. Ocorrem também aulas em que os próprios alunos produzem a sua merenda escolar com os vegetais produzidos na horta e que, depois, são degustados por todos, criando assim uma aprendizagem de forma lúdica, recreativa e de conscientização dos alunos.

\section{Resultados}

O Projeto Oikos, por sua seriedade e compromisso com as atividades que propõe, hoje tem uma grande credibilidade nas escolas e com os professores. Ao assumir o compromisso de responsabilizar-se pela turma, atende todas as demandas que estabelece perante pais, professores e alunos. A seriedade do Projeto é testemunhada e relatada por alguns dos professores que acompanham o Projeto Oikos, conforme os comentários que seguem, extraídos de conversas informais com os professores e com atividades escritas pelos alunos.

Na escola E.M.E.F. Dezidério Fuzer a professora de língua portuguesa responsável pela turma descreve a sensação que tem perante o Projeto Oikos:

\footnotetext{
"Eu tinha muito receio deste projeto, achava que os alunos não iam aderir e como tínhamos muito conteúdo não daria para conciliar os dois assuntos, mas por iniciativa própria dos alunos adiantamos o conteúdo durante a semana que não tem aula do projeto Oikos para que na semana que tem a aula possamos nos dedicar ao Projeto e vejo como os alunos gostam".
}

O depoimento e as atividades dos alunos, da equipe diretiva e dos moradores do Recanto Maestro também mostram o quanto eles vêm aprendendo com o projeto:

\footnotetext{
"Eu estou gostando das aulas do Projeto Oikos! Nós aprendemos muitas coisas legais como: Aprendemos sobre as energias renováveis e não renováveis, reciclagem, dia mundial da água. Fizemos um cata-vento e aprendemos sobre as cores das lixeiras e dia da botânica. E aprendemos muito mais! (aluna Thábata 5. ${ }^{\circ}$ Ano E.M.E.F. Alberto Pasqualini)

" Adoro o projeto Oikos e também aprendi muitas com a professora Raquel Melo! Também ganhamos uma camiseta do projeto Oikos. É muito divertido e legal. Amo o projeto Oikos" (aluna Dominique - 3. ${ }^{\circ}$ Ano E.M.E.F. Santos Reis)

“ Meu Deus recebi uma aula sobre energia renovável de um aluno hoje! Tinha coisa que eu nem sabia!” (Supervisora da escola E.M.E.F. Alberto Pasqualini)

" Onde coloco este copo? Quero jogar agora na lixeira certa. Quero fazer minha parte!" (morador do Recanto Maestro).
} 
Esses depoimentos e muitos outros, que são relatados durante a realização deste projeto, vão mostrando o resultado do trabalho, o quanto é gratificante e quanto alunos, comunidade escolar e comunidade Recanto Maestro vão recebendo e mudando as suas atitudes com relação ao meio ambiente. O Projeto Oikos continua, dia a dia plantando sementes, que germinam. Planta-se amor e sabedoria, colhendo-se esperança e educação.

\section{Referências}

FUNDAÇÃO ANTONIO MENEGHETHI. Anuário dos Projetos Educacionais, Sociais e Culturais da Fundação Antonio Meneghetti. Recanto Maestro. 2016.

ONU, Transformando Nosso Mundo: A Agenda 2030 para o Desenvolvimento sustentável, 2015, Disponível em: https://nacoesunidas.org/pos2015/agenda2030/. Acessado em: 27jul.2017.

MENEGHETTI, Antonio. Pedagogia ontopsicológica. 3.ed - Recanto Maestro, 2014.

MEC/SEF. Parâmetros curriculares nacionais: terceiro e quarto ciclos: apresntação dos temas transversais/ Secretaria de educação Fundamental. Brasília. 1998.

WWF. Muda o mundo, Raimundo! : educação ambiental no ensino básico do Brasil. Brasília. 1997.

REVISTA VISÃO AMBIENTAL. Economia verde - empresas investem em sustentabilidade. São Paulo, Ano 1, n. ${ }^{\circ} 4$ Janeiro/Fevereiro. 2010.

MINISTÉRIO DO MEIO AMBIENTE, Seminário Nacional sobre Agricultura Orgânica. Brasília. 2006. 